\title{
Prevalence and Presentation of Diabetes-Related Hypoglycemia Amongst Persons with Diabetes in a Tertiary Health Instition in Nigeria
}

\author{
Ohenhen Oluwatoyin Abisoye*, Uwameiye Oseribhor \\ Department of Medicine, University of Benin Teaching Hospital, Benin City, Nigeria
}

\section{Email address:}

fashoootee@yahoo.com (O. O. Abisoye)

${ }^{*}$ Corresponding author

\section{To cite this article:}

Ohenhen Oluwatoyin Abisoye, Uwameiye Oseribhor. Prevalence and Presentation of Diabetes-Related Hypoglycemia Amongst Persons with Diabetes in a Tertiary Health Instition in Nigeria. International Journal of Diabetes and Endocrinology. Special Issue: Hypoglycemia in Diabetes. Vol. 5, No. 3, 2020, pp. 34-40. doi: 10.11648/j.ijde.20200503.11

Received: November 23, 2019; Accepted: July 22, 2020; Published: August 18, 2020

\begin{abstract}
Background: Hypoglycaemia is the most common acute complication of Diabetes Mellitus and often treatmentlimiting, serious adverse effect of intensive diabetes therapy. Although it is preventable, hypoglycaemic episodes, especially if severe or recurrent may result in significant psychosocial dysfunction and lower quality of life. Aim: To determine the prevalence, frequency and timing of diabetes-related hypoglycaemia amongst persons with diabetes mellitus. Methods: This was a cross-sectional observational study involving patients attending the diabetes clinic and selected using systematic random sampling. An interviewer- administered questionnaire was used to obtain socio-demographic characteristics as well as experience of hypoglycaemia in the past 12 months and severity graded. Data analysis was performed using SPSS 21.0 , IBM SPSS Statistics, New York, USA Result: A total of 216 patients were recruited for the study. Eighty nine patients (41.2\%) reported experiencing hypoglycaemia, out of which $46(51.7 \%)$ occurred in the morning before breakfast and 16 (18.0\%) experienced severe Hypoglycaemia. Skipped meal (58.4\%) and overdose of GLA (31.5\%) were the most common recognized causes of hypoglycaemia. Level 1 hypoglycaemia was the commonest grade of hypoglycaemia, while males and those on insulin alone had higher odds of having hypoglycaemia $(\mathrm{P}=0.059)$. Conclusion: The reported prevalence of hypoglycaemia amongst persons with diabetes mellitus within the last one year prior to the study was rather high which shows that hypoglycaemia is a common experience amongst type 2 diabetic undergoing management. Continuous patient education on the risks, causes, symptoms, and treatment of hypoglycaemia as well as self-monitoring of blood glucose is recommended for every person with diabetes at every health visits.
\end{abstract}

Keywords: Hypoglycaemia, Prevalence, Severity, Glucose Lowering Agent

\section{Introduction}

Diabetes mellitus (DM) is a major health problem worldwide [1]. Studies have revealed a significant worldwide increase in the incidence and prevalence of diabetes [2-6], with the International Diabetes Federation (IDF) projecting that there will be an increase in persons with DM from 463 million in 2019 to 700 million by 2045 [1].

Strict control of diabetes is increasingly emphasized after the benefits demonstrated in the UK Prospective Diabetes Study (UKPDS) and The Diabetes Control and Complications Trial (DCCT) studies in preventing complications $[7,8]$.
Intensive therapy has been noted to effectively delay the onset and slow the progression of complications like diabetic retinopathy, nephropathy and neuropathy in patients with Type 1 diabetes [7, 8]. Hypoglycaemia is a very common complication and often "treatment-limiting" serious adverse effect of intensive diabetes therapy. Although preventable, hypoglycaemic episodes, especially if severe or recurrent may result in increased cardiovascular morbidity and mortality, significant psychosocial dysfunction as well as reduced quality of life [9]. 
In Nigeria, the late diagnosis of diabetes and lack of regular monitoring of patients coupled with inequalities in accessing care, leads to early presentations of diabetic complications [10]. These issues may also lead to patients commencing medications without prescription from qualified health personal or without regular monitoring of blood glucose or Self-Monitoring of Blood Glucose (SMBG), especially for those on insulin secretagogues and insulin and this can be complicated by hypoglycaemia.

Hypoglycaemia is most convincingly documented by Whipple's triad: symptoms consistent with hypoglycemia, a low plasma glucose concentration at the time of the symptoms, and reversal of those symptoms when the plasma glucose concentration is corrected to normal [9]. The American Diabetes Association defines hypoglycaemia as blood glucose of less than or equal to $70 \mathrm{mg} / \mathrm{dl}$. [9]. The American Diabetes Association Workgroup on Hypoglycaemia describes the classification of hypoglycaemia as [9]: 1) Severe hypoglycemia- An event requiring assistance of another person to actively administer carbohydrate, glucagons, or other resuscitative actions. 2) Documented symptomatic hypoglycemia- An event during which typical symptoms of hypoglycemia are accompanied by a measured plasma glucose concentration $\leq 70 \mathrm{mg} / \mathrm{dl}(3.9$ mmol/l). 3) Asymptomatic hypoglycemia- An event not accompanied by typical symptoms of hypoglycemia but with a measured plasma glucose concentration $\leq 70 \mathrm{mg} / \mathrm{dl} \quad(3.9$ $\mathrm{mmol} / \mathrm{l})$. 4) Probable symptomatic hypoglycemia- An event during which symptoms of hypoglycemia are not accompanied by a plasma glucose determination (but that was presumably caused by a plasma glucose concentration $\leq 70 \mathrm{mg} / \mathrm{dl}$ [3.9 mmol/1]). 5. Relative hypoglycemia- An event during which the person with diabetes reports any of the typical symptoms of hypoglycemia, and interprets those as indicative of hypoglycemia, but with a measured plasma glucose concentration $>70 \mathrm{mg} / \mathrm{dl}(3.9 \mathrm{mmol} / \mathrm{l})$ [9].

The recent American diabetes association (ADA)/ European association for the study of diabetes (EASD) 2018 classification of hypoglycaemia classifies hypoglycaemia as follows [11];

Level Glycaemic criteria/description

Level 1 Glucose $<70 \mathrm{mg} / \mathrm{dL}(3.9 \mathrm{mmol} / \mathrm{L})$ and glucose $\geq$ $54 \mathrm{mg} / \mathrm{dL}(3.0 \mathrm{mmol} / \mathrm{L})$

Level 2 Glucose $<54 \mathrm{mg} / \mathrm{dL}(3.0 \mathrm{mmol} / \mathrm{L})$

Level 3 A severe event characterized by altered mental and / or physical status requiring assistance

Another classification and grading for hypoglycaemia is the Ademolu's classification of hypoglycaemia $(\mathrm{ACH})$ which is classified as;

Hypoglycemia Grade 1 (mild): 55-70mg/dl

Hypoglycemia Grade 2 (moderate): $40-54.9 \mathrm{mg} / \mathrm{dl}$

Hypoglycemia Grade 3 (severe): $10-39.9 \mathrm{mg} / \mathrm{dl}$

Hypoglycemia Grade 4 (very severe): $<10 \mathrm{mg} / \mathrm{dl}$

Symptomatic hypoglycaemia above $70 \mathrm{mg} / \mathrm{dl}$ is a subset of grade 1 in the Ademolu's classification, while asymptomatic grade 4 is referred to as "Ademolus Phenomenon" [12]

\section{OBJECTIVES}

This study was conducted with the aim of determining the prevalence of diabetes-related hypoglycaemia amongst persons with diabetes mellitus, with specific objectives to determine the frequency and timing of diabetes-related hypoglycaemia amongst persons with diabetes mellitus.

\section{Methods}

The study was a hospital-based cross $^{-}$sectional study at the diabetes clinic of University teaching hospital in Benin City, Nigeria where an average of 100 persons with diabetes mellitus are seen at the in-patients and out-patients clinics weekly. After selecting a random number between 1 and 5, every fifth patient entering the clinic was included using systematic random sampling technique. Type 1 and type 2 Diabetic patients who are known to have diabetes for more than 6 months were included in the study.

\subsection{Data Collection Procedure}

An Interviewer-administered questionnaire was used to obtain information on the socio- demographic characteristics of the patients, duration of diabetes and their current treatment, the possible symptoms of hypoglycaemia, its frequency, duration, severity, possible precipitating factors, the remedial measures that patients undertook as well selfmonitoring of blood glucose practices.

\subsection{Statistical Analysis}

Data entry and analysis of the variables was done using Statistical Package for Social Sciences (SPSS) version 21 (IBM Corporation, Somers, New York, USA) software. Descriptive statistics of proportion, mean, and standard deviation was calculated for the socio-demographics characteristics, symptoms, frequency and causes of hypoglycaemia. The odds ratios and the 95\% confidence intervals (CI) were calculated. A p value $<0.05$ was considered as significant for all analysis.

\section{Results}

A total of 216 diabetic patients consisting of $86.1 \%$ outpatient and 97.2\% T2DM patients participated in this study. Participants age ranged from 34 - 91 years with majority $(68.1 \%)$ of the participant between 55 and 74 years, $27.8 \%$ were $<55$ years of age, and the remaining $4.1 \%$ were $>78$ years. The mean age was calculated to be $60.9 \pm$ 10.6. Female patients constituted majority $(63.4 \%)$ of the study participants. One hundred and fifty four $(71.3 \%)$ of the study participants practiced Self-Monitoring of Blood Glucose (SMBG) out of which majority (50.7\%) of them monitored their blood glucose more than 3 times a week as shown in Table 1.

Out of the 216 study participants, 89 had experienced hypoglycaemia giving a prevalence rate of $41.2 \%$. Over half of the respondents, $(51.7 \%)$ who reported to have 
experienced hypoglycaemia, reported hypoglycaemia occurring early hours of the day before breakfast while 13 study participants each $(14.6 \%)$ reported post breakfast and before bed time respectively and this represented in Figure 1. The frequency of Hypoglycaemia is displayed in Figure 2 which shows most participants experienced hypoglycaemia at least 1- 3 times in a month. The most common symptom of hypoglycaemia in this study was weakness $(27.8 \%)$, followed by sweating $(25 \%)$, then hunger $(21.3 \%)$ as shown in Figure 3.

Table 1. Socio-demographics and clinical profile of patients.

\begin{tabular}{|c|c|c|}
\hline Variable & Frequency (216) & Percent (\%) \\
\hline \multicolumn{3}{|l|}{ Age group (years) } \\
\hline $34-44$ & 13 & 6.0 \\
\hline $45-54$ & 47 & 21.8 \\
\hline $55-64$ & 82 & 38.0 \\
\hline $65-74$ & 65 & 30.1 \\
\hline $75-84$ & 8 & 3.6 \\
\hline 85 and above & 1 & 0.5 \\
\hline \multicolumn{3}{|l|}{ Mean $(\mathrm{SD})=60.9 \pm 10.6$} \\
\hline \multicolumn{3}{|l|}{ Gender } \\
\hline Male & 79 & 36.6 \\
\hline Female & 137 & 63.4 \\
\hline \multicolumn{3}{|l|}{ Serial Monitoring of RBG } \\
\hline Yes & 154 & 71.3 \\
\hline No & 62 & 28.7 \\
\hline Periodicity of Serial Monitoring of RBG & $\mathrm{n}=154$ & \\
\hline Twice a week & 51 & 33.1 \\
\hline Thrice a week & 25 & 16.2 \\
\hline$>$ Thrice a week & 78 & 50.7 \\
\hline
\end{tabular}

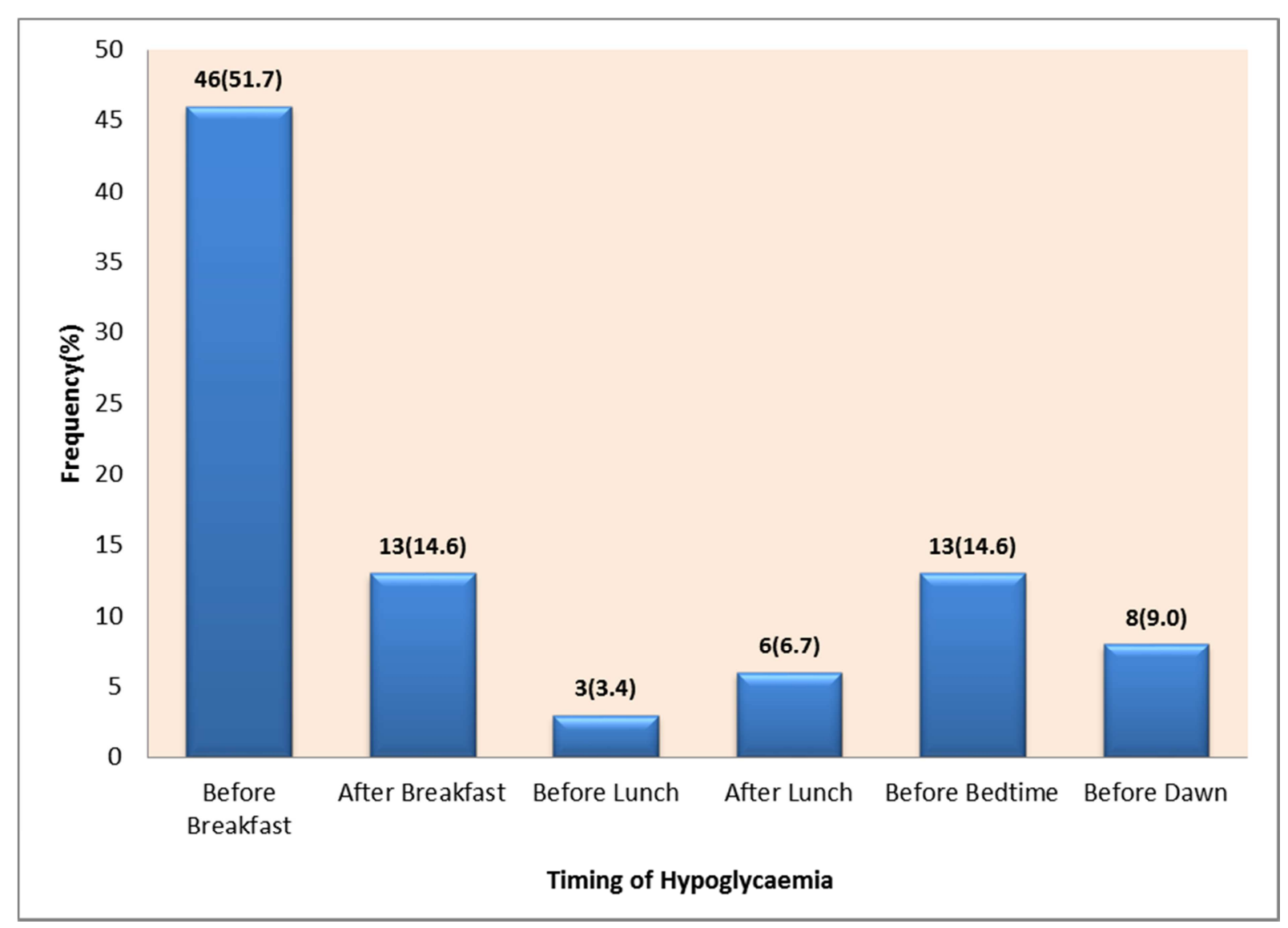

Figure 1. Timing of Hypoglycaemia. 


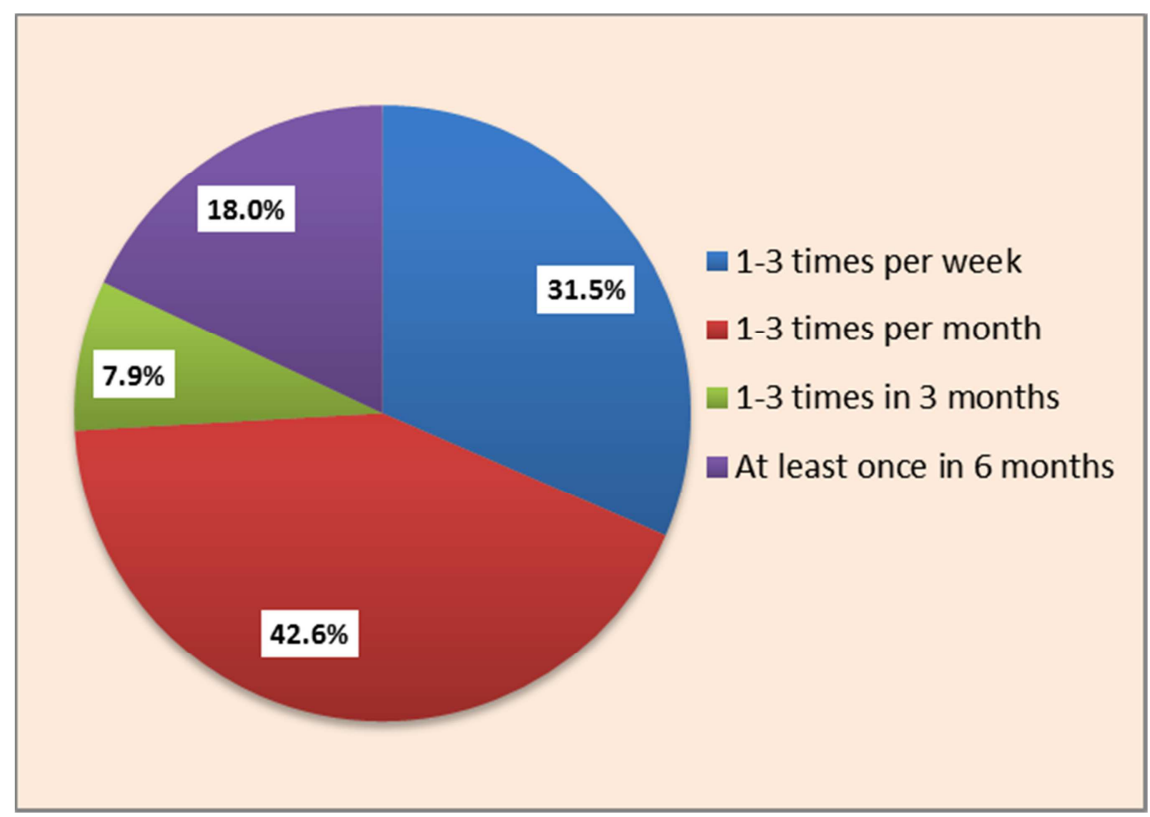

Figure 2. Frequency of Symptoms of Hypoglycaemia.

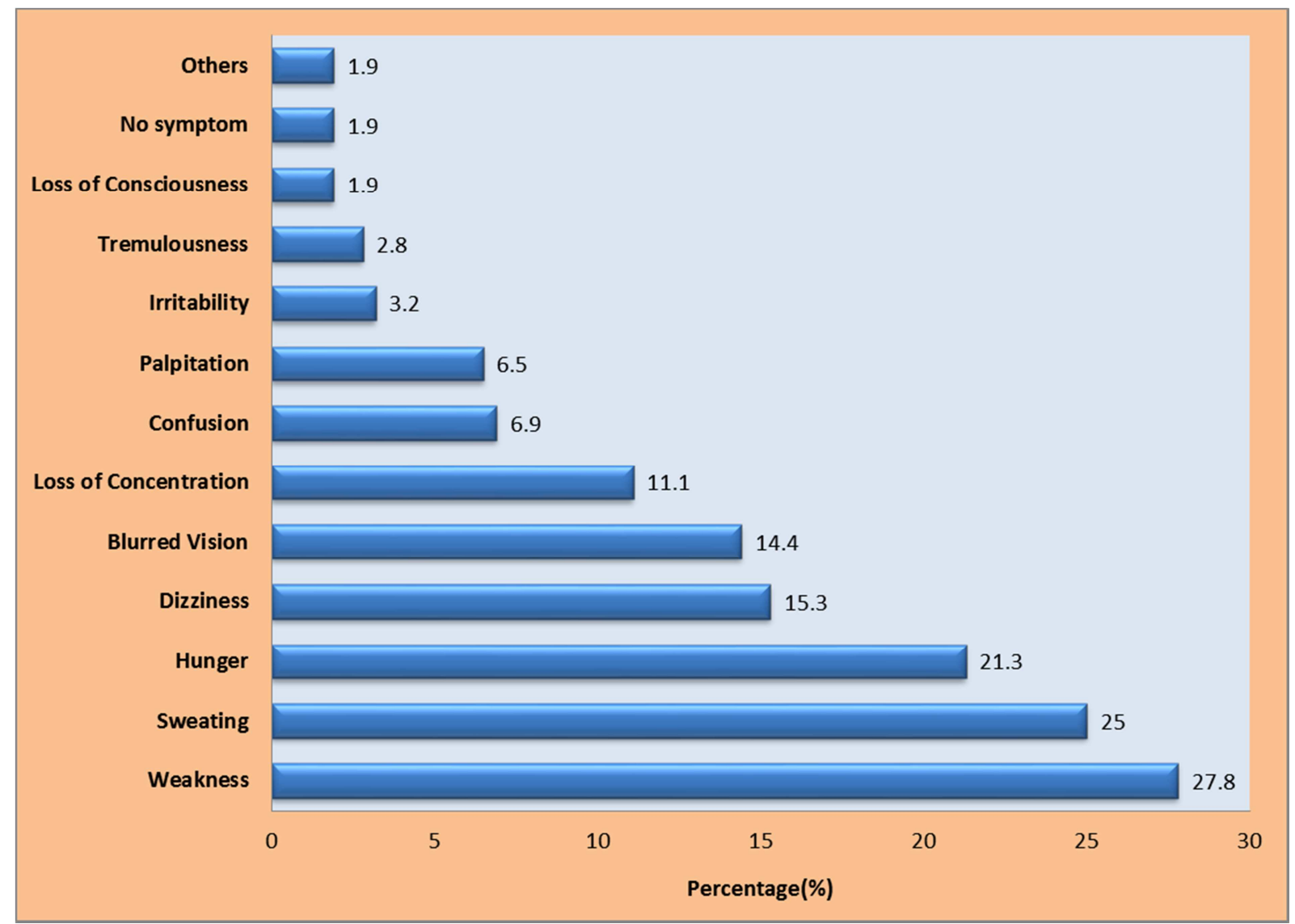

Figure 3. Prevalence of Symptoms of Hypoglycaemia.

With regards to the severity of Hypoglycaemia amongst study participants, using Ademolu's classification of Hypoglycaemia, 48 persons $(53.9 \%)$ had mild hypoglycaemia while, 37 persons $(41.6 \%)$ and $4(4.5 \%)$ had moderate and severe hypoglycaemia respectively. Similarly the ADA/EASD classification criteria showed most of those that had hypoglycaemia had level 1 hypoglycaemia $(52.8 \%)$ while level 3 and level 2 were reported by $18 \%$ and $29.2 \%$ of respondents respectively However, using the clinical classification of hypoglycaemia, documented hypoglycaemia was reported by $71(79.8 \%)$ while severe and asymptomatic hypoglycaemia was reported by $16(18 \%)$ and $2(2.2 \%)$ of 
study participants respectively as shown in Table 2 .

The causes, treatment options and complication following hypoglycaemic event are displayed in Table 3. Skipping meals was the most reported cause of hypoglycaemia $(58.4 \%)$, while the most commonly used treatment option is taking of glucose drink (47.1\%). Out of the eighty nine persons that had hypoglycaemia, $54(60.7 \%)$ where on only oral glucose lowering agents while $29(32.6 \%)$ where on Insulin and oral glucose lowering agents $(\mathrm{P}=0.182)$. Also 58 persons $(65.2 \%)$ of those that had hypoglycaemia were in the age group 54-73years, however this was not statistically significant $(\mathrm{P}=0.388)$ (Table 4$)$. Males $(\mathrm{P}=0.059)$ and those on insulin alone had higher odds of having hypoglycaemia however this was not statistically significant $(\mathrm{P}=0.059$, and $\mathrm{P}=0.380$ respectively) as shown in Table 5 .

Table 2. Classification of hypoglycaemia.

\begin{tabular}{lll}
\hline Variable & Frequency (89) & Percent \\
\hline Severity of Hypoglycaemia (ACH) & & \\
Grade 1 (Mild) & 48 & 53.9 \\
Grade 2 (Moderate) & 37 & 41.6 \\
Grade 3 (Severe) & 4 & 4.5 \\
ADA Clinical Classification & & \\
Severe hypoglycaemia & 16 & 18.0 \\
Documented hypoglycaemia & 71 & 79.8 \\
Asymptomatic hypoglycaemia & 2 & 2.2 \\
*ADA/EASD Classification & & \\
Level 1 & 47 & 52.8 \\
Level 2 & 26 & 29.2 \\
Level 3 & 16 & 18.0 \\
\hline
\end{tabular}

*ADA=American Diabetes Association, $\mathrm{ACH}=$ Ademolus classification of Hypoglycaemia.

Table 3. Causes of hypoglycaemia and treatment options of hypoglycaemic events.

\begin{tabular}{lll}
\hline Variable & Frequency $\mathbf{n = 8 9}$ & Percent \\
\hline Causes of Hypoglycaemia & & \\
Skipped meals & 52 & 58.4 \\
Overdose of GLA & 28 & 31.5 \\
Unaccustomed exercise & 10 & 11.2 \\
Treatment options & & \\
Glucose drink & 42 & 47.1 \\
Carbohydrate meal & 11 & 12.4 \\
Glucose drink and meal & 20 & 22.5 \\
IV Glucose infusion in Hospital & 16 & 18.0 \\
\hline
\end{tabular}

GLA=Glucose lowering Agent.

Table 4. Association between socio-demographic/glucose lowering agents and hypoglycaemia.

\begin{tabular}{lllll}
\hline \multirow{2}{*}{ Variables } & \multicolumn{2}{l}{ Experienced Hypoglycaemia } & \multirow{2}{*}{$\chi^{\mathbf{2}}$} & \multirow{2}{*}{ P-value } \\
\cline { 2 - 3 } & No n=127 (\%) & Yes n=89 (\%) & & \\
\hline Gender & & & & \\
Male & $40(31.5)$ & $39(43.8)$ & & \\
Female & $87(68.5)$ & $50(56.2)$ & & 0.064 \\
Age (years) & & & & \\
$34-53$ & $25(19.7)$ & $24(27.0)$ & 1.891 & 0.388 \\
$54-73$ & $88(69.3)$ & $58(65.2)$ & & \\
$74-93$ & $14(11.0)$ & $7(7.9)$ & & \\
$\begin{array}{l}\text { Duration of DM } \\
\leq 5\end{array}$ & $52(40.9)$ & $28(31.5)$ & 3.564 & 0.168 \\
$6-10$ & $29(22.8)$ & $30(33.7)$ & & \\
$>10$ & $46(36.2)$ & $31(34.8)$ & & \\
\hline
\end{tabular}

\begin{tabular}{lllll}
\hline \multirow{2}{*}{ Variables } & \multicolumn{2}{l}{ Experienced Hypoglycaemia } & \multirow{2}{*}{$\chi^{\mathbf{2}}$} & \multirow{2}{*}{ P-value } \\
\cline { 2 - 3 } & No n=127 (\%) & Yes n=89 (\%) & & \\
\hline Glucose Lowering & Agent & & 3.409 & 0.182 \\
Oral Alone & $91(71.7)$ & $54(60.7)$ & & \\
Insulin Alone & $4(3.1)$ & $6(6.7)$ & & \\
Insulin + Oral & $32(25.2)$ & $29(32.6)$ & \\
\hline
\end{tabular}

Table 5. Logistic regression for predictors of hypoglycaemia among the respondents.

\begin{tabular}{llll}
\hline Predictors & $\begin{array}{l}\text { P } \\
\text { value }\end{array}$ & $\begin{array}{l}\text { Odds } \\
\text { ratio }\end{array}$ & 95\% CI) for OR \\
\cline { 4 - 4 } Gender & & & \\
Male & 0.059 & 1.761 & $0.98-3.17$ \\
Female* & & 1 & \\
Age (years) & & & \\
$34-53$ & 0.237 & 1.998 & $0.64-6.29$ \\
$44-73$ & 0.621 & 1.286 & $0.47-3.49$ \\
$\geq 74 *$ & & 1 & \\
Duration of DM & & & \\
$\leq 5$ & 0.251 & 0.666 & $0.33-1.33$ \\
6-10 & 0.318 & 1.430 & $0.71-2.89$ \\
$>10 *$ & & 1 & \\
Glucose Lowering Agent & & & \\
Oral Alone & 0.480 & 0.793 & $0.42-1.51$ \\
Insulin Alone & 0.380 & 1.875 & $0.46-7.63$ \\
Insulin + Oral* & & 1 & \\
\hline
\end{tabular}

*Reference category.

\section{Discussion}

This was a cross-sectional study carried out with the aim of determining the prevalence, frequency and timing of diabetes-related hypoglycaemia amongst persons with diabetes mellitus. The prevalence of hypoglycaemia in this study was $41.2 \%$ which is rather high. In a similar study in South-Eastern Nigeria [13], a slightly lower prevalence of $35.2 \%$ was reported, while in South-Western Nigeria, researchers reported that approximately $50 \%$ of Type 2 diabetics in their study had experienced symptoms of hypoglycaemia in the preceding 6months to the study [14]. In a prospective German study to assess the incidence and predictors of hypoglycaemia, an incidence rate of $14.1 \%$ was reported for any severity hypoglycaemia over a follow-up of 12 months. [15] This reported figure aside being an incidence rate was for only severe hypoglycaemia which was defined as hypoglycaemia resulting in patients seeking medical attention or requiring hospital admission. Vanishree et al in India, reported that $96 \%$ of persons with type $2 \mathrm{DM}$ in their study had reported at least one symptom of hypoglycaemia [16]. With regards to the presentation of hypoglycaemia, weakness, sweating and hunger were the most common symptoms in this study. These findings are similar to those reported by Olamoyegun et al where shivering, sweatiness and hunger were the commonest symptoms of hypoglycaemia in their study [14]. In the study conducted in India, weakness was the commonest symptom, then dizziness and drowsiness [16]. Adrenergic symptoms of hypoglycaemia (like anxiety, irritability, dizziness, 
diaphoresis, pallor, tachycardia, headache, shakiness, and hunger) when present, precede neuroglycopenic features of hypoglycaemia (like impaired concentration, confusion, disorientation, irritability, lethargy, slurred speech, and irrational or uncontrolled behaviour), thus functioning as an early warning system [17]. However, when sympathetic dysfunction (e.g., diabetic autonomic neuropathy) exists or when adrenergic blockers are being used, these signs and symptoms may be unnoticeable [17]. For most of the patients, the precipitating factor was missing meals followed by overdose of glucose lowering agents. Hypoglycaemia was severe requiring in-hospital treatment with intravenous infusion in nearly a fifth of the patients in this study while nearly half of the study participants treated with glucose drinks and this is largely due to the fact that most of the participants had mild to moderate hypoglycaemia. The ADA stresses that individuals at risk for hypoglycaemia should be asked about symptomatic and asymptomatic hypoglycaemia at each encounter. Glucose $(15-20 \mathrm{~g})$ is the preferred treatment for the conscious individual with hypoglycaemia, although any form of carbohydrate that contains glucose may be used. The individual should consume a meal or snack to prevent recurrence of hypoglycaemia [9].

In observing the use of different classification for analysis, that is the Ademolu's criteria and ADA/EASD 2018, it was noticed that according to Ademolu's criteria, Grade 1 was the commonest, followed by Grade 2, then grade 3. Similarly in the ADA/EASD classification, Level 1 was the commonest, followed by level 2, then level 3 . Grade 1 hypoglycaemia is documented to be the commonest grade in diabetics generally as well as in Type 2 diabetics specifically [18]. Grade 4 in the Ademolu's criteria was not recorded in this study and likewise, was also not recorded from a similar African study amongst diabetics [18]. The probable explanation for the seeming rareness of grade 4 hypoglycaemia is that death may have occurred at such very low blood glucose level of less than $10 \mathrm{mg} / \mathrm{dl}$ and thus the diagnosis missed. A larger multicentre study will help to expatiate further on this hypothesis. Grade 3 and level 3 were the least common form of hypoglycaemia. According to the ADA clinical classification of hypoglycaemia in this study, over two-thirds of the participants in this study had documented hypoglycaemia and this is largely attributed to the finding that nearly two- thirds of persons in this study practiced selfmonitoring of blood glucose with over half of them monitoring more than three times a week. Self-monitoring of blood glucose (SMBG) is well established and a highly valuable approach for the daily management of type 2 diabetes mellitus [19]. It also supports preventive strategies of acute and chronic complications of diabetes. In particular, SMBG increases a patient's awareness of hypoglycaemia [20] and therefore provides a potential strategy to trigger selfregulatory prevention of significant hypoglycaemic episodes [21].

Hypoglycaemia occurred more frequently in those on only oral glucose lowering agent when compared to those on insulin alone or insulin and oral glucose lowering agents, but this difference was not significant. In UKPDS prospective multi-center randomized controlled trial among type 2 diabetics on OHAs and/or insulin, the incidence of any severity hypoglycaemia was $17 \%$ among those on glyburide, $11 \%$ among those on chlorpropamide, and $36.5 \%$ among those taking insulin [7]. In another retrospective, cross-sectional analytical study in United States of America conducted among 1055 type 2 diabetics, the prevalence of all hypoglycaemia was $16 \%$ among those taking OHAs and $30 \%$ among those taking insulin [22]. Insulin use alone or in combination with Sulphonylureas has been reported as predictors of hypoglycaemia by some studies [14, 23]. Other reported predictors are older age, duration of diabetes [14]. In the German study to determine the incidence and predictors of hypoglycaemia amongst persons with type 2 diabetes, it was reported that patients with incident hypoglycaemia had longer diabetes duration, higher HbA1c and a more frequent smoking history; more had co-morbid disease conditions such as coronary artery disease, peripheral arterial disease, amputation, heart failure, peripheral neuropathy, diabetic retinopathy and clinically relevant depression at baseline. Multivariable adjusted positive predictors of incident hypoglycaemia over the follow-up were prior anamnestic hypoglycaemia, retinopathy, depression, insulin use and blood glucose selfmeasurement in the same study [15].

\section{Conclusion}

This study shows that the prevalence of hypoglycaemia is high among persons with DM including severe hypoglycaemia requiring assistance for recovery. The major cause was missed meals thus persons with Diabetes Mellitus should therefore be continuously educated on the causes of diabetes related- hypoglycaemia with emphasis on not skipping meals, drug dosing and regimen as well as the importance of self- monitoring of blood glucose.

\section{Limitation}

One the strengths of this study is that the determination of Hypoglycaemia also involved blood glucose estimation at the time of the occurrence of symptoms and the comparisons of various classification of hypoglycaemia. Limitations of this study include its sample size which is small and the crosssectional study design. A larger multi-center longitudinal study is suggested to increase the power of the study. Also, the glucose lowering agents were not individually tested for association with hypoglycaemia as most of the study participants were on various combinations of glucose lowering agents and also varying doses.

\section{References}

[1] International Diabetes Federation. IDF Diabetes Atlas, 9th edn. Brussels, Belgium: 2019. Available at: http://www.diabetesatlas.org. 
[2] Guariguata L, Whiting DR, Hambleton I, et al. Global estimates of diabetes prevalence for 2013 and projections for 2035. Diabetes Res Clin Pract. 2014; 103: 137-49.

[3] Beran D, Yudkin JS. Diabetes care in sub-Saharan Africa. Lancet. 2006; 368: 1689-1695.

[4] Mbanya JC, Motala AA, Sobngwi E, et al. Diabetes in subSaharan Africa. Lancet 2010; 375: 2254-2266.

[5] Ogbera AO, Ekpebegh C. Diabetes mellitus in Nigeria: the past, present and future. World J Diabetes. 2014; 5: 905-911.

[6] Andrew E. Uloko, Baba M. Musa, Mansur A. Ramalan, Ibrahim D. Gezawa, Fabian H. Puepet, Ayekame T. Uloko et al. Prevalence and Risk Factors for Diabetes Mellitus in Nigeria: A Systematic Review and Meta-Analysis. Diabetes Ther. 2018 Jun; 9 (3): 1307-1316.

[7] Intensive blood-glucose control with sulphonylureas or insulin compared with conventional treatment and risk of complications in patients with type 2 diabetes (UKPDS 33). UK Prospective Diabetes Study (UKPDS) Group. Lancet. 1998; 352: 837-853.

[8] The effect of intensive treatment of diabetes on the development and progression of long-term complications in insulin-dependent diabetes mellitus. The Diabetes Control and Complications Trial Research Group. N Engl J Med. 1993; 329: 977-86.

[9] American Diabetes Association Workgroup On Hypoglycemia Defining and Reporting Hypoglycemia in Diabetes: A report from the American Diabetes Association Workgroup on Hypoglycemia. DIABETES CARE. 2005; 5: 1245-1249.

[10] Adeloye D, Ige JO, Aderemi AV, Ngozi A, Emmanuel OA, Asa A, Gbolahan O. Estimating the prevalence, hospitalisation and mortality from type 2 diabetes mellitus in Nigeria: a systematic review and meta-analysis. BMJ Open. 2017; 7: 015424. doi: 10.1136/ bmjopen-2016-015424.

[11] American Diabetes Association. "Standards of Medical Care in Diabetes. Diabetes Care. 2019; 42: S1-S2.

[12] Ademolu AB (2017) Role of Ademolus Classification of Hypoglycemia in Blood Glucose and Diabetes Mellitus Management. Gastroenterol Liver Clin Med. 2017; 1: 1003.

[13] Gabriel Uche Pascal Iloh, Agwu Nkwa Amadi. Epidemiology of hypoglycemia among ambulatory Type 2 diabetic patients in a primary care clinic of a tertiary hospital in Southeastern Nigeria. Journal of health research and reviews in developing countries. 2018; 5: 57-65.
[14] Olamoyegun MA, Ayodele A O, Enikuomehin A C, Akinlade AT. Incidence and Determinants of Reported Hypoglycaemia among Patients with Type 2 Diabetes Mellitus in a Tertiary Health Institution in Nigeria. Journal of Diabetes Mellitus. 2020: 10 ; 51-63.

[15] Tschöpe D, Bramlage P, Binz C, Krekler M, Deeg E, Gitt AK. Incidence and predictors of hypoglycaemia in type 2 diabetes - An analysis of the prospective DiaRegis registry. BMC Endocr Disord. 2012; 12: 23-30.

[16] Vanishree Shriraam, Shriraam Mahadevan, M. Anitharani, Nalini Sirala Jagadeesh, Sreelekha Bhaskara Kurup, T. A. Vidya, and Krishna G. Seshadri. Reported hypoglycemia in Type 2 diabetes mellitus patients: Prevalence and practices-a hospital-based study. Indian J Endocrinol Metab. 2017 JanFeb; 21 (1): 148-153.

[17] Donna T. Detection, Prevention, and Treatment of Hypoglycemia in the Hospital Diabetes Spectrum. 2005; 18: (1) $39-44$.

[18] Adegbenga B Ademolu. "Analysis of Hypoglycemic Episodes in Diabetics in Africans Using Ademolus Classification of Hypoglycemia (ACH)". Acta Scientific Medical Sciences. 2019: 138-145.

[19] Schnell O, Alawi H, Battelino T, et al. Self-monitoring of blood glucose in type 2 diabetes: recent studies. J Diabetes $S c i$ Technol. 2013; 7 (2): 478-488.

[20] Schnell O, Alawi H, Battelino T, Ceriello A, Diem P, Felton A, Grzeszczak W, Harno K, Kempler P, Satman I, Vergès B. Consensus statement on self-monitoring of blood glucose in diabetes: a European perspective. Diab Metab Heart. 2009; 18 (4): 285-9.

[21] Peel E, Parry O, Douglas M, Lawton J. Blood glucose selfmonitoring in non-insulin-treated type 2 diabetes: a qualitative study of patients' perspectives. Br J Gen Pract. 2004 Mar; 54 (500): 183-8.

[22] Miller CD, Phillips LS, Ziemer DC, Gallina DL, Cook CB, ElKebbi IM. Hypoglycemia in patients with type 2 diabetes mellitus. Arch Intern Med. 2001; 161: 1653-1659.

[23] Sun-Young P, Eun Jin J, Ju-Young S, Min-Young L, Donguk K, Eui-Kyung L. Prevalence and Predictors of Hypoglycemia in South Korea.. American Journal of Managed Care. 2018; 24 (6): 278-286. 